ITEJ Juli-2020, Volume 5 Nomor 2 Page 88 - 96

e IAIN SYEKH NURJATI CIREBON
ITEJ

Information Technology Engineering Journals eISSN : 2548-2157

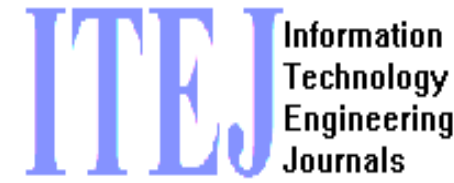

Url : https://syekhnurjati.ac.id/journal/index.php/itej

Email : itej@syekhnurjati.ac.id

\title{
Design and Implementation of Web-Based Helpdesk Information Systems Using Extreme Programming Methods
}

\author{
Freddy Wicaksono \\ Program Studi Teknik Informatika \\ Universitas Muhammadiyah Cirebon \\ Freddy.wicaksono@umc.ac.id
}

\author{
Orin Satriani Baswara \\ Program Studi Teknik Informatika \\ Universitas Muhammadiyah Cirebon \\ orinsatriani@gmail.com
}

\begin{abstract}
Technological developments have become a necessity for job optimization, be it desktop, web or mobile-based software, of course this really supports work with fast, timely completion, without spending a lot of effort and money. The Help Desk is a facilitator for the process of solving operational problems, through communication and interaction networks, internal and external, between the source of the problem (the client) and the potential / problem solving analysis capacity (experts) so that the Asset Management process becomes more effective in improving unit performance. Its operational implementation refers to the principles in the concept of Knowledge Management. Extreme programming is a method that lightens the burden or speeds up the software development process, the characteristics of this method are in accordance with this study which has a small number of team members. This method is flexible so that it can adapt to the changes that customers want. With this the user becomes easier for system development
\end{abstract}

Keywords : Extreme Programming, helpdesk

\section{INTRODUCTION}

\subsection{Background of the Problem}

Technological developments using software have now become a necessity optimizingwork, be it desktop, web or mobile-based software, of course this really supports the work with fast completion, on time, without spending a lot of effort and money.

PT. Fath Technology Solution is one of the private companies in Cirebon City that has been engaged in warehouse software and hardware services since 2017. One of the business fields that has been busy being handled is hardware service which is currently experiencing a decline since June 2019 , when the company moved to a location that is located in the Griya Sunyaragi Permai (GSP) housing, besides that, if you look at the data and facts from the beginning of 2020 until now, the decline in the number of services is increasingly significant starting from March to May 2020 due to the lockdown of the global pandemic "Covid-19".

\subsection{Problem Identification}

From the description of the background of the problem above, the writer can identify the problem as follows: 
1. When the administration does not come to work the situation is not conducive because often customers who come are handled temporarily by different technicians and the administration is overwhelmed in recapitulating reports.

2. Transaction data has not been computerized so The admin should check the pile of archive check sheets and repair installations it takes time to search when needed

3. The customer doesn't know the extent of progress workmanship of the goods it serves is being handled

4. The hardware service business of PT. Fath Technology Cirebon experienced a significant decline since June 2019 and during the 3 month lockdown during the Covid-19 pandemic requires a new innovation to increase the quantity and quality of service

\subsection{Problem Formulation}

From the identification of the above existing problems, the authors formulate the following problems:

1. How to design an information system support work with fast, timely completion, without spending a lot of effort and money?

2. How is the implementation of the information system so that all transactions become neatly computerized data?

3. How to accommodate customer needs in order to know the progress of the work on the goods being serviced?

4. What innovations are suitable for increasing the quantity and quality of PT.Fath Technology Cirebon's services?

\subsection{Problem Limitation}

So that the discussion of the problems carried out can be well directed, the authors limit the problems to be discussed, namely:

1. Designing a web-based information system using the PHP programming language and Code Igniter Framework and MySQL database.

2. The method used in designing this information system is the Extreme Programming (XP) method.

3. This web-based helpdesk information system focuses on the features needed by technicians, admins and customers.

4. Display using Responsive Bootstrap, HTML, CSS, JS.

5. Making a web-based helpdesk information system is carried out at PT. Fath Technology Cirebon.

\subsection{Research Objectives}

The purpose of making this product is to design and implement a Web-Based Helpdesk Information System Using the Extreme Programming Method which is expected to be useful for improve service quality of PT.Fath Technology Cirebon.

\section{BASIC THEORY}

\subsection{Design Definition}

According to Beta $(2008$, p. 5), design is a creative process in solving a problem in matters relating to the design of an object that is functional or aesthetic. Which in principle looks at the technical aspects, functions, materials, without giving up the elements of color, line, texture, balance of composition and form

\subsection{Implementation Definition}

According to Whitten, Bentle, \& Barlow (1993), system implementation is a process for placing and applying information in operations

Implementation is directed to activities, actions, or system mechanisms. Implementation is not just activities, but activities and to achieve the goals of planned activities (Usman, 2002: 70).

\subsection{Definition of Information Systems}

According to James O'Brien (2010, p26), a system is a group of interconnected components, working together to achieve goals along with receiving input and producing output in an orderly transformation process.

\subsection{Definition of the Helpdesk}

According to Wooten (2001, p5) Help Desk is a formal organization that provides support function to users of the companies product, services, or technology. Or the Help Desk is part of a company that provides documents on product, service or technology functions from that company.

\section{How the helpdesk works:}

1. Front End (User)

Starting with the user or it can be called the Front End who is having a problem with the program he is using. When he or she doesn't know how to fix it, the user contacts the Help Desk and submits a complaint via phone, web, or email.

2. Helpdesk 
Level 1 Help Desk also responds to complaints experienced by users and tries to solve the problem. Help Desk level 1 is the lowest level of a Help Desk. At this level, the user's problems were taken care of by junior technicians. If the junior technicians can't solve the problem, they will send a notification to the specialist (Back End) as soon as possible so that the problem is quickly resolved.

3. Back End (Specialist)

After notification from Help Desk level 1 is delivered, Help Desk level 2 will be responsible for user problems.

Admin Help Desk (Level 2) is commonly referred to as Admin Help Desk. Admin Help Desk will solve user problems more effectively, efficiently, and will produce the right solution which will then be conveyed to the user.

Engineer (Level 3) If the user does not understand the explanation given by the Admin Help Desk or indeed the Help Desk is required to visit the customer's house, the Engineer or Help Desk level 3 is the final solution to solving a problem. Engineers are technicians who will directly visit the user's location so that problems can be quickly resolved.

\section{Helpdesk advantages:}

Help Desk has an important role for the company and society. Here are the advantages:

1. Help Desk can increase customer confidence in a company in handling customer inquiries and complaints.

2. Help Desk can solve problems experienced by customers in a short time.

3. The Help Desk can resolve all customer questions and complaints because those questions and complaints are recorded by the Help Desk.

4. Help Desk can arrange the division of tasks to company staff.

5. Help Desk can make a progress report on the performance of staff and leaders.

\section{Helpdesk aims as a concept:}

The Help Desk is a facilitator for the process of solving operational problems, through communication and interaction networks, internal and external, between the source of the problem (client) and the potential / problem solving analysis capacity (expert) so that the Asset Management process becomes more effective in improving unit performance. Its operational implementation refers to the principles in the concept of Knowledge Management.

\section{The purpose of the helpdesk as a system:}

Help Desk is a collaborative network of various related parties which is managed following agreed procedures and mechanisms. Its operations are supported by infrastructure: organization, experts and web-based technology, to support monitoring functions as well as on-line and real-time problem solving processes.

The Help Desk will provide the following benefits:

○ continuity monitoring and communication on-line and in real time

- facilitate collaborative problem solving

- facilitate synergy among stakeholders

$\circ$ facilitation of personnel for assessment and supervision

○ development of data-bank (e-Library) problems and solutions

\subsection{Definition of the Web}

The definition of a website according to Hakim Lukmanul (2004) is an internet facility that connects documents within the scope 90eman or long distance. Documents on the website are called web pages and the links on the website allow users to move from one page to another (hyper text), both between pages stored on the same server and servers around the world. Pages are accessed and read through browsers such as Netscape Navigator, Internet Explorer, Mozilla Firefox, Google Chrome and other browser applications.

\subsection{Definition of Extreme Programming}

According to Pressman (2010) the software engineering method is an object-oriented approach to the Extreme Programming (XP) model. The development paradigm includes a set of rules and practices that occurin the context of the framework of four activities, namely: planning, design, coding, and testing. These four activities will produce a software based on the concept of the Extreme Programming model.

\section{RESEARCH METHOD}

\subsection{Data Collection Methods}

On This research the writer uses descriptive research method, which is a method that describes a situation or problem that is happening based on the facts or data obtained, collected at the time of carrying out the research.

The data collection techniques used in this study were carried out in various ways, including: 


\section{a. Observation}

Collecting data by making direct observations of the object of research, by recording important things related to the title of the report, in order to obtain complete and accurate data.

b. Interview

Collecting data by communicating and interviewing directly with related parties such as the author conducting interviews with admin staff and technicians of PT. Fathtech Cirebon.

c. Literature review

Collecting data from written sources by reading, studying and recording important things related to the problem being discussed in order to obtain a theoretical picture.

\subsection{Systems Development Method}

The method used by the author in the development of information systems at PT Fathtechnology Cirebon is Extreme Programming from Agile, this method is methods that lighten the load or speed up the software development process, the characteristics of this method match this research which has a small number of team members. This method is flexible so that it can adapt to the changes desired by the customer. In addition, this method has a low risk so that the system development carried out to make the helpdesk application can run well.

\section{ANALYSIS AND SYSTEM DESIGN}

\subsection{System Analysis}

System analysis represents an information system that is intact into various parts of its components with the intention of being able to identify or evaluate various kinds of problems and obstacles that will arise in the system so that later countermeasures, improvements or development can be done

\subsection{Problem Analysis}

Service goods service process at PT. Fath Technology IT Solution, administration is still done manually, so data is not well computerized, takes time in decision making, data is slow to search, and customers cannot find out the obstacles or developments of the goods being serviced.

\subsection{Analysis of Current System Procedures}

The system procedure runs the process of receiving service goods starting from the customer coming to bring the goods then the admin records and gives to the technician after that the technician works on the servicean goods and when the technician is finished submitting to the admin, then the admin contacts the customer.

For an overview of the running system can be seen in the image below:

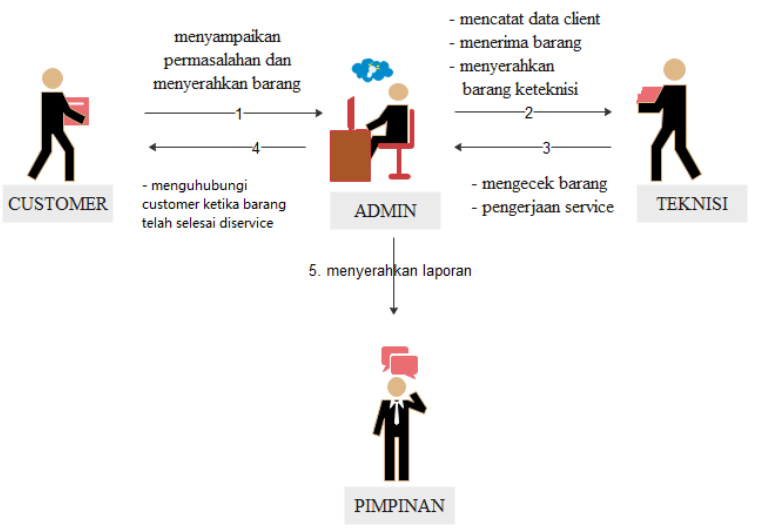

Figure 1 Overview of the Running System

The following is an explanation of the current helpdesk as described earlier:

1. Customers make phone calls / go to the admin to notify complaints or problems they are experiencing.

2. Admin records customer problems and makes notes and hands over service items to technicians.

3. Technicians report service items to the admin if there are problems or when they are finished.

4. Admin makes customer phone calls if there are problems or notifies if the goods being serviced are finished.

5. At the end of the month the admin submits the leadership report data.

\subsection{Analysis of the system being developed}

IdeaThe input and output data specifications that will be processed in this system are as follows:

1. Ideainput data identification 
In building a helpdesk information system data that must be entered into the system, namely the administrator must enter the master data, and all transaction data required by the helpdesk application which will later become data input, while the customer must enter a username and password or scan the QR Code that has been given by the administrator so that can know the progress of the goods being serviced and can provide feedback. The technician will enter information related to service items. Leaders can get reports in real time.

2. IdeaData Output Identification

Sethe user has entered the data needed by the system, the system will display data information in accordance with what has been entered into the system.

The following is an overview that will be developed by the author:

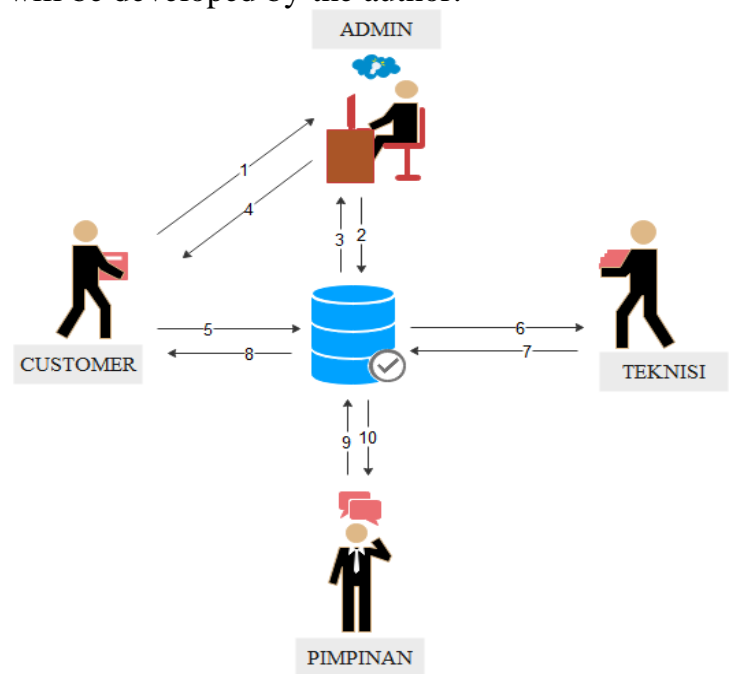

Figure 2 Overview of the System to be Developed

The following is an explanation of the helpdesk which will be developed as previously described:

1. Customer make a phone call / go to the admin to notify complaints or problems experienced.

2. Admin input customer data, input transactions into the system.

3. Output of customer or admin username and password can print customer QRcode.

4. Admin submits the username, password or Print the QR Code card to the customer.

5. Customers log into the system and can find out the progress of completing the goods being serviced, customers can also communicate or feedback with technicians.

6. Admin receives work information on service goods.

7. Technicians input work progress and can inform service items if there are problems.

8. Customers get information related to the goods being serviced.

9. Leader login system and request report

10. Leaders get information related to report data.

\subsection{System Design Architecture}

The design architecture is designing a system that contains data processing process steps and procedures to support system operation, in other words as the decomposition of a complete system into parts of a system to be able to identify problems that occur and it is hoped that improvements from the system

PThe helpdesk information system design process consists of processing input data such as master data in the form of user data, agency data, customer data, technician data, and transaction data.The system can run on computers and smartphones using a browser as a translator for HTML, CSS, Bootstrap (system interface), PHP (data processing) and MySQL files as the database stored on a server connected via the internet network.

Below is a description of the system design architecture: 


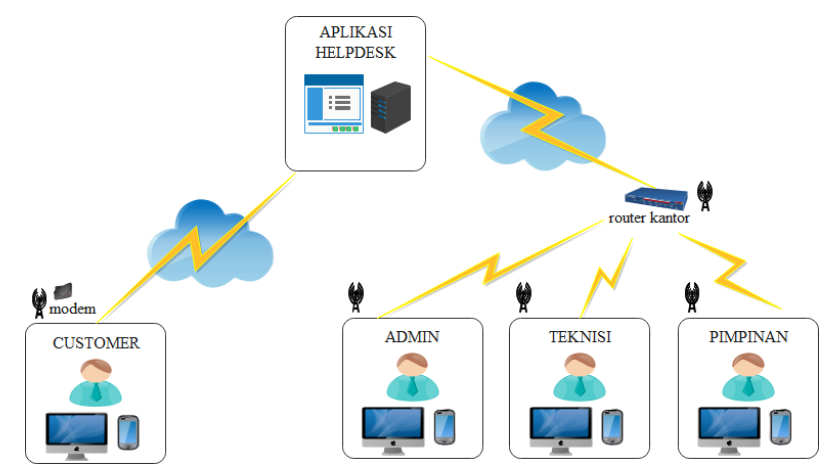

Figure 3 Helpdesk Information System Design Architecture

\subsection{System Overview}

The Helpdesk Information System uses the Extreme Programming (XP) method from Agile. In general, it is a websitebased application that can be used by administrators, customers, technicians and leaders. Administrators use this system to enter master data in the form of user data, agency data, customer data, technician data, and transaction data, while the customer uses this application to find out the progress of the work on the goods being serviced and can also convey technical feedback, while technicians use the system. This is to process information on the development of goods being serviced and can provide feedback on the obstacles faced, the leader uses this system to request real time report data.

\section{ANALYSIS OF SYSTEM REQUIREMENTS}

System requirements analysis determines all the requirements that exist in the complete system. Analysis of system requirements is divided into two, namely functional requirements analysis and non-functional requirements analysis. The making of this application has standard specifications in terms of hardware and software.

\subsection{Functional Requirements Analysis}

Analysis of functional requirements is a need where users can access whatever the system can do as desired.

a. The system must be able to input related data with data

$>$ Administrator, Customers, Technicians and Leaders can log into the system.

$>$ Administrator can enter master data in the form of user data, agencies, customers, technicians.

$>$ Administrator can enter transaction data.

$>$ Customer can submit complaints / feedback.

$>$ Customer can know the progress of the goods being serviced.

$>$ Technicians can report problems that occur.

b. The system must be able grant access permission.

$>$ Administrator can manage users.

$>$ Administrator can manage agencies.

$>$ Administrator can manage data service.

$>$ Administrator can manage transaction data.

$>$ Technicians can process feedback to customers.

c. The system must be able to generate reports.

$>$ Leaders can view reports.

\subsection{Analysis of Non-Functional Requirements}

Analysis of non-functional requirements is a minimum requirement, consisting of operational, security, information and performance requirements.

a. Operational

$>$ System User Hardware and Software

- Used on the Microsoft Windows $10 \circledR$ operating system.

- Memory requirements 2048 MB RAM.

- Printer for printing reports.

- Router to provide internet connection.

- Browser Applications Like Chrome, Mozilla.

$>$ System Developer Hardware and Software

- HP EliteBook Folio 9470m Laptop ..

- Microsoft Windows 1064 bit Operating System. 
- Core i5 processor.

- 4GB RAM memory.

- Visual Studio Code.

- Browser Applications Like Chrome, Mozilla.

- Edraw Max 7.9

b. Security

$>$ Equipped with a password to access the system.

There are differences in access rights to access features in the system.

Adding users to MySQL for database security.

c. Information

$>$ Displayed to inform if the username or password entered is wrong.

Used to provide indication of data changes.

$>$ Used to display existing data.

d. Performance

$>$ The placement of employees is faster because it is done automatically by the system (computerized).

> The ranking process uses the Profile Matching method by matching employee data and placement criteria.

The data entry process is carried out using a personal computer or laptop in a LAN (Local Area Network) network.

\section{SYSTEM PLANNING}

At this design stage, UML is used, one of the diagrams used is the Use Case as shown below:

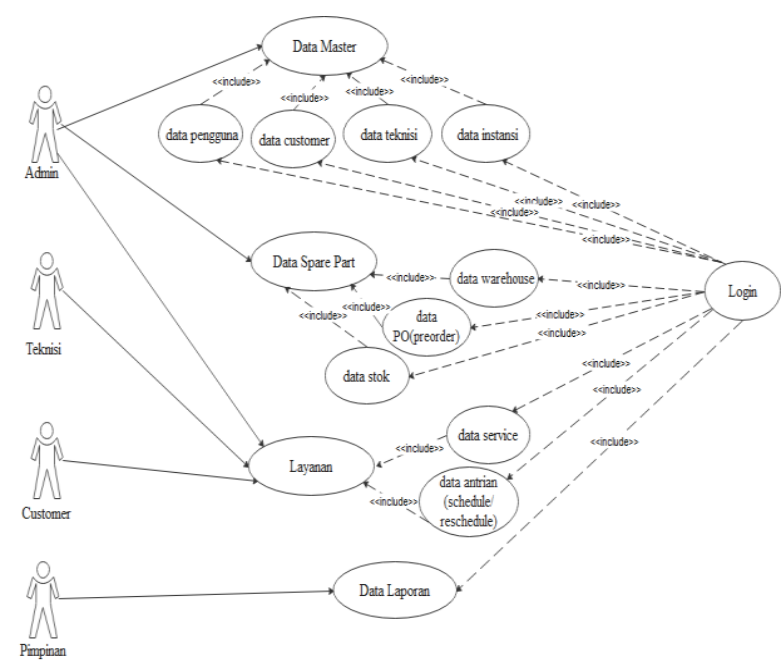

Figure 4 Usecase Diagram of Helpdesk Information System

The following is an explanation of Figure 4:

1. Administrator, has the functionality:

a. Login

b. Managing Master Data

- Manage user data

- Manage agency data

- Manage technician data

- Manage customer data

c. Managing Spare Part Data

- Manage stock data

- Manage preorder data

- Manage the data warehouse

d. Manage Service Data

- Manage queue data (schedule / reschedule)

- Manage data service

2. Actor Technician, has the following functionality:

a. Login

b. Manage Services 
- Processing data service information

- Provide feedback data service

\section{Actor Customer, has functionality}

a. Login

b. Service Monitoring

- Get queue data (schedule / reschedule)

- Seeing the progress of the work of the item being serviced

- Provide feedback on items being serviced

4. Lead Actor, has functionality
a. Login
b. Report Data
- Request and View Report Data

\subsection{Use of Applications}

\section{RESULTS AND DISCUSSION}

Applications generated from the System Web-Based Helpdesk Information Using Extreme Programming Method is a system that makes it easy every customer to get information about what are the constraints, the stages of handling the goods being serviced, and computerized data so that data storage is not piled up and makes it easier to find data when needed.

Applications made are still within the scope of localhost, so before using this application, on a PC or laptop, a web server such as AppServer, WAMP, or XAMPP must be installed, then import the MySQL database from this application, and activate the web server.

\section{Login Page Views}

The initial stage of opening the application will appear the main page in the form of a login form. The displayed page is as shown in Figure 5

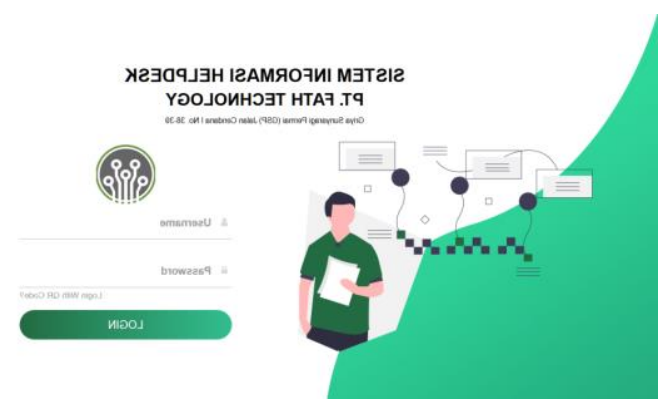

Figure 51 Login Page Views

In Figure 5, login is used to log in admin, customer, technician and leadership

\section{Admin Page Views}

On the admin page, there is a main page, which is the page that appears after the admin logs in.

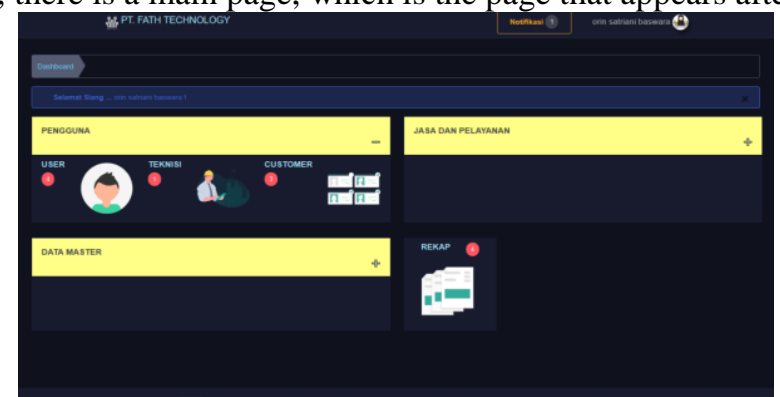

Figure 6 Admin Main Page Display

In Figure 6 is a page that contains buttons for accessing the applications provided, such as Users, Technicians, Customers, Reports and so on. Next there is a display of each menu on the picket teacher's main menu.

\section{CONCLUSIONS}

Based on the descriptions in the previous chapters, the conclusions that the authors can draw include: 
1. Users can perform CRUD functions properly and have a validated system so that they are able to support work with effective, efficient completion and save the use of printed report data.

2. All transaction data that have been successfully inputted into a database can be found easily and quickly whenever needed by typing the transaction code in the search column.

3. Customers can see the progress that the technician is working on by logging in using the username and password that the admin has given then when successfully entering the dashboard then the customer enters the service code in the search column then waits for a while until the information data appears according to the service code.

4. The helpdesk information system implementation is in accordance with the needs of PT. Fath Technology Cirebon City and one of the benefits it feels is an added value for customer trust because of the transparency of its progress service.

\section{REFERENCES}

[1] Agus Irawan, Nanda Krisna Setiyorini. 2017. "Design and Build a helpdesk Application Using a Knowledge Management System Approach in the Technician Section of PT. Indah tips for pulp \& paper tbk ", ProTekInfo Journal, Vol. 4

[2] Alfian, Yumi Novita Dewi, Firstianty Wahyuhening Fibriany, Harsih Rianto, Adika May Sari. 2020. "Design of Information System for Ticketing Helpdesk at DPMPTS Pemprov DKI Jakarta", JURIKOM (Journal of Computer Research), Vol. 7 No. 2

[3] Ali Mustopa. 2017. "Web-Based It-Helpdesk Information System at Yogyakarta Amikom University", Journal of Informatics and Computers (JIKO), Vol. 2 No. 2

[4] Delia Mediana, Andi Iwan Nurhidayat. 2018. "Designing a Web-Based Helpdesk (A-Desk) Application Using the Laravel Framework (Case Study at Pdam Surya Sembada City Surabaya)", Journal of Informatics Management. Vol 8 No 02

[5] Eno Rizqi Shabrina, Intan Della Rusvita, Intan Sari Riyandini, Sarwati Rahayu. 2018. "Service Application System to Accomodate Requests for the Information Technology Department (Case Study: Pt. Aivon Mediatama)", Journal of Cendikia, Vol. XVI

[6] Evasaria M. Sipayung, Cut Fiarni, Ernest Aditya. 2017. "Designing a Helpdesk Information System Using the ITIL V3 Framework", JNTETI, Vol. 6 No. 2

[7] Irfan Santiko, Titin Nur Prihatiningsih. 2017. "Implementation of Service Features And Repair At Pt. Telkom WebBased Area IV Maintenance Service Center (Msc) ”, Pelita Nusantara Management and Informatics Junal, Vol 21 No. 1

[8] Rezania Agramanisti Azdy, Arsia Rini. 2017. "Implementation of Extreme Programming in Building Customer Service Complaint Applications (Palapa) in Higher Education", Journal of Information Technology and Computer Science (JTIIK), Vol. 5, No. 2

[9] Ryan Muhammad Bahrudin, Mohammad Ridwan, Hardjito S Darmojo. 2019. "Implementation of the Helpdesk Ticketing System in Handling Complaints on the Use of Web-Based Information Systems", JUTIS, Vol. 7 No. 1

[10] Ummi Azizah Rachmawati, Syarifu Adam, Syarif Husain Alwi. 2019. "Development of a Web-Based Helpdesk Ticketing System (Case Study: Yarsi University)", Journal of Information Technology YARSI (JTIY) ", Vol. 6 